\title{
Sexualidades dissidentes: um olhar sobre narrativas identitárias e estilo de vida no ciberespaço
}

\author{
Dissident sexualities: an outlook on identity narratives \\ and lifestyle in cyberspace
}

Vera Lucia Marques da Silva ${ }^{1}$

${ }^{1}$ Programa de PósGraduação em Saúde Pública, Escola Nacional de Saúde Pública Sérgio Arouca, Fiocruz. Av. Brasil 4036/700, Manguinhos. 21040-361 Rio de Janeiro RJ Brasil.

veramarques@fiocruz.br
Abstract The subculture of BDSM (Bondage, Discipline, Domination, Submission, Sadism, Masochism) is organized around dissident erotic practices based on consent. Starting with a netnography survey, this study seeks to understand how adepts of BDSM present themselves from the standpoint of identity in cyberspace. In this sense, blogs and sites related to BDSM, as well as social networks, have been observed. Added to this material are interviews of adepts in other media. Techniques of Saturation Sampling and Discourse Analysis were applied. By eroticizing power, they construct erotic games based on hierarchies, where one individual occupies the role of domination and the other of submission. However, beyond a mere sexual role, the adepts argue that both domination and submission are part of their own nature, revealing an essentializing and instituting discourse, which they claim to be a sexual orientation. From specific scenarios, dress and sexual paraphernalia, their practitioners relive their social traumas, particularly those involving gender oppression. In spite of the stigma that is attributed to the subjects involved, their narratives echo from some of the pillars of contemporary subjectivity, such as valuation of experience, of self-development, and of the maximization of pleasure. Key words Eroticism, Sexuality, BDSM
Resumo A subcultura BDSM (Bondage, Disciplina, Dominação, Submissão, Sadismo, Masoquismo) organiza-se em torno de práticas eróticas dissidentes, pautadas no consentimento. A partir de uma netnografia, este estudo visa apreender como os adeptos de BDSM se apresentam do ponto de vista identitário no ciberespaço. Neste sentido, blogs e sites relacionados ao BDSM foram acompanhados, bem como redes sociais. Somam-se a este material, entrevistas de adeptos em outras mídias. Técnicas de amostragem por saturação $e$ Análise de Discurso foram aplicadas. Ao erotizarem o poder, constroem jogos eróticos pautados em hierarquias, onde um indivíduo ocupa o papel de dominação e o outro, de submissão. Todavia, para além de um mero papel sexual, os adeptos defendem que tanto a dominação quanto a submissão fazem parte de sua própria natureza, revelando um discurso essencializador ou instaurando o que afirmam ser uma orientação sexual. A partir de cenários, vestimentas e apetrechos sexuais especificos, seus praticantes ressignificam traumas sociais, particularmente os que envolvem a opressão de gêenero. A despeito do estigma que marca os sujeitos envolvidos, suas narrativas bebem de alguns dos pilares da subjetividade contemporânea, dos quais se destaca, a valorização da experiência, do desenvolvimento de si e da maximização do prazer.

Palavras-chave Erotismo, Sexualidade, BDSM 


\section{Introdução}

Este artigo insere-se no campo da Saúde Coletiva que busca compreender as formas pelas quais a sociedade identifica e analisa suas necessidades e problemas de saúde, assim como se organiza para enfrentá-los ${ }^{1}$. Neste sentido, a Saúde é compreendida em seu sentido amplo, ou seja, como um estado de completo bem-estar físico, mental e social. Uma das dimensões de reflexão e atuação deste campo refere-se à Promoção da Saúde. Esta age sobre os condicionantes e determinantes sociais da saúde (DSS) que se relacionam a fatores sociais, econômicos, políticos e culturais, coletivos e individuais. Por conta disto, os DSS não podem ser avaliados somente pelas doenças geradas, pois vão além, influenciando todas as dimensões do processo de saúde das populações, tanto do ponto de vista do indivíduo, quanto da coletividade na qual ele se insere ${ }^{2}$. Desta forma, é importante atentar-se para os mecanismos de produção das iniquidades. Isto inclui olhar para as iniquidades que, porventura, possam ser geradas por diagnósticos patologizantes que estigmatizam indivíduos.

Neste sentido, este trabalho objetiva conhecer a subcultura BDSM no Brasil no espaço virtual, particularmente no que se refere às narrativas que constituem sua(s) identidade(s) e fundamentam seu estilo de vida. BDSM é um acrônimo que deve ser lido sempre em pares, ou seja, BD significa Bondage e Disciplina, DS, Dominação e Submissão, e SM, Sadomasoquismo. Vale esclarecer, ainda que de forma sucinta, do que se tratam estas práticas.

Bondage ou imobilização é realizada, em geral, com o uso de cordas, algemas ou correntes. Os praticantes podem fazer uso de roupas especiais, capazes de constranger movimentos do corpo ou mesmo apertá-lo. Vendas, mordaças e capuzes também são comuns e se destinam à restrição dos sentidos. Há diversas técnicas de amarração do corpo, entre elas, o shibari japonês, muito semelhante ao origami. Bondage e disciplina relacionam-se a fantasias eróticas que envolvem castigos e punições. O par "D" e "S" envolve fantasias de dominação e submissão por meio de humilhação e violação. Ao longo desta pesquisa verificou-se que o par DS é central e nomeia seus praticantes a partir da posição que ocupam nos jogos eróticos como dominadores ou submissos. Por fim, tem-se as práticas de sadomasoquismo, que agregam atividades que se utilizam de dor para obter estímulos eróticos.

Tratam-se, portanto, de sexualidades consideradas dissidentes, ou seja, que estão à margem do que Gayle denominou "círculo encantado". No interior deste estão as sexualidades legitimadas socialmente e em seu exterior encontramse as sexualidades não reprodutivas, homossexuais, fora do casamento, realizadas em lugares públicos, entre gerações, pornográficas, sadomasoquistas. Vale ressaltar que estudos acerca destas sexualidades, que transcendam a "patologia", são bastante escassos no campo da Saúde Coletiva.

A subcultura BDSM pauta-se pelo princípio denominado SSC - Seguro, São e Consensual. "Seguro" significa não correr riscos sem as devidas precauções. "São" requer que os praticantes estejam de posse de todas as faculdades mentais, assim como emocional e intelectualmente equilibrados. "Consensual" refere-se à necessidade de um acordo prévio entre os envolvidos acerca das práticas que realizarão. A necessidade deste consentimento exclui, portanto, as práticas de pedofilia, necrofilia e zoofilia.

Apesar de algumas de suas práticas, como a do sadomasoquismo erótico, serem consideradas pelo Manual Diagnóstico e Estatístico de Transtornos Mentais, ou, no original em inglês, Diagnostic and Statistical Manual of Mental Disorders $(\mathrm{DSM})^{4}$, como patológicas, percebe-se que o grupo se organiza a partir da defesa da Saúde como princípio básico de suas práticas. No Brasil, ao menos até 2015, esta defesa ainda não se constituía em uma agenda política pela despatologização destas práticas, o que já acontece em outros países do mundo, inclusive nos Estados Unidos. Em 2013, uma nova revisão do DSM foi lançada. A preparação desta revisão se fez a partir da constituição de grupos de pesquisadores de diferentes partes do mundo, que foram incumbidos, cada qual, de rever grupos de transtornos específicos. O grupo responsável pela revisão dos transtornos parafílicos, ao fim de seu trabalho, apresentou uma série de argumentos, pautados nos resultados de diversas pesquisas, em defesa da despatologização do sadomasoquismo erótico, conforme Reiersol e Skeid ${ }^{5}$. No entanto, seu parecer não foi acolhido pela Associação Americana de Psiquiatria, permanecendo, portanto, no DSM.

Este Manual, cuja primeira edição ocorreu em 1952, tem origem no famoso compêndio Psychopathia Sexualis do psiquiatra Krafft-Ebbing, publicado em 1886. Krafft-Ebbing escreve no bojo da preocupação da medicina a respeito das "perversões" sexuais que tem início com o minucioso estudo acerca da homossexualidade ${ }^{6}$. O discurso sexual médico nessa época era profundamente moralista e sexista, segundo Leite Júnior ${ }^{7}$, e fortemente centralizado na reprodução. O gozo era 
desvalorizado até mesmo para fins de procriação: afinal, bastava ao homem um breve gozo e, à mulher, este era totalmente dispensável. O que ia além disso, sem justificação biológica, passou a ser enquadrado como perversão. No hall das perversões, surge o sadismo e o masoquismo. Cabe ressaltar que até este momento histórico, tanto o sofrimento físico quanto o mental eram cultuados pela tradição judaico-cristã, não sendo considerados, portanto, nem pecado, nem doença.

O termo sadismo encontra sua inspiração na obra literária do Marquês de Sade, significando uma aberração horrível da devassidão, um sistema monstruoso e antissocial que afronta a natu$\mathrm{reza}^{7}$. Já o termo masoquismo surge da obra literária de Sacher-Masoch. A partir do século XIX, ambos os termos passaram a definir sexualidades consideradas desviantes do padrão normal, ou seja, relações genitais heterossexuais entre adultos. Esses “desvios” ao longo do século XX se transformaram em patologias e, posteriormente, em transtornos mentais. Vale ressaltar que o sadismo próprio da filosofia de Sade nada tem a ver com o sadismo praticado pelo grupo BDSM, uma vez que aquele defendia que o prazer deveria ser conquistado à força, nunca de forma consensual, como defendido no BDSM. Já no masoquismo de Sacher-Masoch, cabe à mulher, a posição de dominadora, que, no entanto, deve ser treinada e estar à altura do escravo. Já nas relações BDSM, a posição de dominação não possui gênero, podendo, portanto, ser desempenhada por homens ou mulheres. Interessante o fato de que, quando Krafft-Ebing publica em 1886 a primeira edição de seu compêndio, o sadismo torna-se a forma patológica da tendência masculina à dominação e o masoquismo transforma-se em seu oposto e vai apontar para a tendência patológica de submissão da mulher. A mulher, que era dominadora na obra literária de Sacher-Masoch, torna- se a submissa patológica em um "passe de mágica”. Inclusive, a relação de casos de masoquistas apresentados em seu livro revela o predomínio de homens: de um total de 37 casos, 33 são de homens e 4 de mulheres. Esse predomínio de homens masoquistas levou o autor a concluir que se tratavam de homens "parcialmente afeminados" e que o masoquismo era uma forma rudimentar de "antipatia sexual". Com isso, esses casos acabaram por se tornar clinicamente mais importantes que o sadismo, pois transgrediam a regra de que é o homem naturalmente quem domina a mulher, e parecia na época haver um número enorme de masoquistas, principalmente nas grandes cidades.
Vale ressaltar que o campo da Medicina e das ciências Psi perpassam o campo da Saúde Coletiva, na medida em que este se constitui a partir de práticas e saberes interdisciplinares voltados para a promoção, a prevenção e o cuidado da saúde da população. Esta amplitude demanda interdisciplinaridade para, por meio dela, tentar compreender os processos sociais de produção da saúde/ doença. É a partir desta compreensão que a análise aqui proposta se desenvolve. Por isto, deixa-se a alcunha do patológico para buscar a origem da subcultura BDSM.

Em sua análise acerca da relação sadomasoquista de um casal vitoriano e a forma como dramatizaram as mudanças sociais de sua época, McClintock $^{8}$ situa o nascimento da subcultura sadomasoquista na Europa por volta do fim do século XVIII, com a emergência da era industrial. No entanto, os jornalistas Brame et al. ${ }^{9}$, que produziram um amplo levantamento acerca das práticas sexuais que envolvem a dominação e a submissão, relatam o surgimento do BDSM, tal como se expressa e articula hoje, tendo início entre as décadas de 1940 e 1950 nos Estados Unidos, por meio de um grupo de homens gays que se intitulavam "Movimento Leather". Os Leathers adotavam uma estética marcada pelo uso do couro e comungavam de princípios militares e disciplinares oriundos da carreira militar de vários deles, buscando recriar a camaradagem, o risco e a adrenalina experimentada na Segunda Guerra Mundial. Rubin e Butler ${ }^{10}$ esclarecem que leather é uma categoria ampla que congrega homens gays com práticas distintas: sadomasoquistas, praticantes de penetração anal com o punho, fetichistas e homens gays másculos que preferem parceiros masculinos.

Uma das maiores referências do cenário sadomasoquista norte-americano, Califia ${ }^{11}$ revela a história do sadomasoquismo lésbico em São Francisco, dos anos 1960 ao início da década de 1980. Seu relato denuncia a luta do grupo pelo respeito às suas práticas e as tensões entre o grupo e as feministas antipornografia, assim como com o meio homossexual.

Já o sadomasoquismo heterossexual, ainda conforme Rubin, organizou-se por quase todo esse período em torno de anúncios sexuais, dominação profissional e alguns clubes sociais privados. Para esse grupo, o leather era um fetiche inserido em um imaginário de elementos predominantemente femininos, e os poucos caracteres masculinos existentes, geralmente, eram efeminados. Weiss ${ }^{12}$ data o surgimento de comunidades fetichistas, de bondage e de spanking (técnica erótica de disci- 
plinamento que faz uso de palmadas, por exemplo) também na década de 1950. Segundo ela, em diversos lugares dos EUA, esses grupos, predominantemente formados por heterossexuais, permanecem separados da comunidade BDSM.

No Brasil, os primeiros clubes sadomasoquistas surgem anos depois. Segundo Leite Júnior ${ }^{7}$ podem ser datados a partir da década de 1980 . Existem hoje os munches (sem tradução para o português), que são reuniões informais promovidas por praticantes do BDSM para conhecer pessoas novas, inclusive as "curiosas" - aquelas interessadas em informações -, e as festas, algumas já tradicionais, que reúnem o grupo, sendo que a cidade de São Paulo parece ser o local brasileiro de maior badalação. Esboçadas algumas linhas que permitem entender a partir de que grupos sexuais o BDSM atual se constitui, sigo caminho apresentando a metodologia utilizada nesta pesquisa.

\section{Metodologia}

O conteúdo empírico analisado neste artigo é parte de etnografia virtual desenvolvida para minha tese de doutoramento ${ }^{13}$. O material que ora é apresentado, de domínio público e irrestrito, pautou-se nas seguintes atividades: a) acompanhamento de blogues e sites nacionais; e b) observação de páginas das redes sociais Facebook e FetLife - sendo esta última uma rede específica de praticantes BDSM. Desta forma, certas características próprias da linguagem escrita destes espaços podem ser percebidas, ou seja, ora a linguagem é mais coloquial e abreviada, típica das páginas de redes socais, ora melhor escrita, melhor controlada, como em blogues que visam explicitamente promover uma maior compreensão das práticas BDSM entre adeptos e interessados. Dois esclarecimentos se fazem mister.

$\mathrm{O}$ primeiro diz respeito à questão do respeito à ética na pesquisa. A Resolução número 510, de 07 de abril de 2016, do Conselho Nacional de Saúde ${ }^{14}$, preconiza que pesquisas que utilizam informações de domínio público estão desobrigadas de registro e avaliação por Comitês de Ética em Pesquisa, bem como pela Comissão Nacional de Ética em Pesquisa. O trabalho ora proposto está amparado, portanto, por esta determinação. No entanto, a fim de assegurar o total anonimato dos usuários, ainda que reconhecendo que estes façam uso de apelidos no espaço virtual, optouse por nomeá-los apenas pelo termo "Adepto", seguido de letra alfabética.
O segundo ponto refere-se à seleção do conteúdo a ser examinado. Os blogues e sites visitados foram escolhidos a partir das duas primeiras páginas de sugestões apresentadas pelo aplicativo de busca do Google, uma vez que, teoricamente, são os mais visitados da internet. Em tal busca, palavras-chave como "BDSM", "dominação" e "submissão", por exemplo, foram utilizadas. Aplicou-se na coleta de material empírico a técnica de amostragem por saturação e em sua análise, a técnica de Análise de Discurso, conforme Minayo ${ }^{15}$ em referência a Pêcheux, uma vez que se comunga da ideia de que o sentido de uma palavra não existe por si mesmo. Todavia, revela posições ideológicas em jogo no processo sócio-histórico, no qual as relações são produzidas.

A este trabalho de pesquisa na internet, desenvolvido ao longo dos anos de 2013 a 2015, somou-se a revisão bibliográfica de material publicado em âmbito nacional e nos EUA. Algumas entrevistas de praticantes em outros meios, como revistas e jornais, também foram secundariamente consideradas na análise. Esse esforço objetivou cotejar algumas informações e a linguagem utilizada, a fim de conhecer mais amplamente o universo BDSM, tal como se expressa no mundo virtual.

Acerca de pesquisas no espaço virtual, é preciso considerar que a internet se tornou um importante meio de comunicação mundial, disseminando informações e estreitando laços entre pessoas e diferentes culturas. Contudo, quando as práticas estudadas e seus sujeitos são marcadas pelo estigma, a internet se apresenta como um locus de estudo por excelência graças ao alto grau de anonimato que envolve os internautas. Este é o caso do BDSM. Sendo uma subcultura marcada pelo estigma, na qual a guarda de um segredo comum congrega seus praticantes, pode-se inferir a importância do ciberespaço tanto para o fortalecimento do grupo e a disseminação de seu estilo de vida, quanto para a viabilização desta pesquisa.

Outro aspecto relevante diz respeito à adaptação do método etnográfico para o ambiente virtual. A etnografia virtual também tem sido chamada de netnografia. Este neologismo, segundo Fragoso et al. ${ }^{16}$, foi cunhado na década de 1990 e popularizado por Kozinets em seu trabalho sobre fãs. No Brasil, as discussões de Sá no início dos anos 2000 começaram o debate sobre as aplicações da netnografia. Para o autor, a utilização deste termo marca a existência de naturezas distintas e adaptações entre a etnografia presencial e as experiências online, ainda que se 
considere que as interações sociais virtualizadas são indissociáveis dos contextos onde ocorrem ${ }^{16}$.

Desta forma, para dar conta dos objetivos delineados para este artigo, sua organização se constitui em três partes. Na primeira, objetiva-se perscrutar como o BDSM se apresenta no ciberespaço de uma perspectiva identitária, tanto como grupo, quanto acerca das personas que o formam. Posteriormente, alguns elementos das narrativas reflexivas que embasam o estilo de vida BDSM são abordados relacionando-as com aspectos específicos da contemporaneidade. Na terceira e última parte deste trabalho, as palavras finais.

\section{BDSM e a apresentação de si}

Atualmente, o BDSM está fortemente presente no ciberespaço, local onde pode trocar experiências, conversar, buscar parceiros entre si, de forma mais livre, uma vez que se sente protegido pelo anonimato dos apelidos utilizados na internet em salas de bate-papo e redes sociais. Tal apelido cumpre também, nesse caso, a função de sinalizar as preferências sexuais do praticante. Assim, nomes como DOM EXPER SP, Masoquista SP (H), Papai Severo SP, podem ser encontrados, indicando não só o papel desempenhado dentro da subcultura BDSM, como também sua localização geográfica e sexo. Curiosamente, a despeito de em sua origem o BDSM envolver praticantes gays, no Brasil, particularmente nos limites do ciberespaço pesquisado, eles raramente foram localizados. Um olhar mais atento é capaz de discernir também a presença de adeptos, propriamente ditos, mas também de neófitos, aqueles que estão apenas conhecendo pessoas do meio, algumas práticas, ritos etc. Nesse sentido, a internet oferece uma grande riqueza de material informativo e pedagógico acerca dos elementos que envolvem o universo BDSM. Segundo Zilli ${ }^{17,18}$, que também se debruçou sobre a presença do BDSM na internet, esse material se organiza em um formato classificado como Manual. Os "manuais" caracterizam-se por afirmar, por exemplo:

a) o BDSM como um conjunto de práticas sexuais relacionadas a um "estilo de vida";

b) a necessidade de manter um bem-estar físico e psicológico para o exercício dessas práticas de forma segura e consentida;

c) a preocupação com o estigma de perversão sexual e consequente busca por dialogar com a psiquiatria para fins de legitimação de suas práticas.

A respeito do item a) elencado por Zilli, no qual a sigla BDSM designa uma reunião de prá- ticas sexuais que configuram um "estilo de vida", merece destaque a reflexão de Giddens ${ }^{19}$ acerca da escolha pessoal que está implícita no estilo de vida. Conforme salienta o autor, um estilo de vida pode ser definido como um conjunto de práticas, em alguma medida, integradas, rotinizadas, incorporadas nos modos, por exemplo, de vestir, comer, encontrar pessoas, e que dão forma material a uma narrativa reflexiva particular da autoidentidade do indivíduo que o adota. Implica, portanto, em uma escolha dentro de várias outras opções possíveis. O estilo de vida é "adotado" e não "outorgado", o que provavelmente explica a existência dos dois importantes instrumentos do BDSM analisados por Zilli, dicionário e manual, ambos a serviço da divulgação de um estilo de vida que, assim como outros, pode ser adotado.

Além dos aspectos acima identificados por Zilli17 ${ }^{17}$, é possível acrescentar outro elemento a essa listagem: conscientes do estigma social, forjado pela alcunha do patológico, e da possibilidade de uso da identificação BDSM por pessoas mal intencionadas de fora do grupo, os manuais costumam oferecer orientações voltadas especificamente para iniciantes. Essas orientações referem-se tanto à busca por parceiros, e parece se ocupar em facilitar a diferenciação entre o que o grupo considera "verdadeiros" e "falsos" adeptos, quanto à definição das próprias identidades que compõem o grupo.

Desta forma, em um post publicado pelo Adepto A, uma série de características que ajudam à identificar um verdadeiro dominador são listadas, entre elas tem-se que este estimula a/o submissa/o a buscar sempre mais informações; respeita a/o "serva/o"; sabe receber e dar prazer; é sincero. Esse detalhamento, portanto, que pretende esclarecer os iniciantes e curiosos acerca do BDSM, busca tanto se distanciar de visões preconceituosas, quanto separar os verdadeiros dos falsos adeptos. A informação esclarecida, portanto, contida nos manuais, é vista como uma importante estratégia de proteção dos grupos de BDSM, e está associada ao controle social que o próprio meio exerce sobre si, assunto que será abordado mais adiante.

Os manuais BDSM deixam claro que as relações DS são marcadas por uma erótica em torno da forte assimetria de poder entre os envolvidos, na qual se tem, por um lado, aquele que detém o poder na relação e como tal deverá ser venerado, respeitado e obedecido. Por outro lado, há aquele que se despoja de sua liberdade e autonomia para servir ao detentor do poder. As posições de dominação e submissão são pensadas pelo grupo 
como parte da identidade de cada sujeito. A dominação está na natureza do dominador, assim como a submissão faz parte da essência da pessoa que se submete.

Neste jogo tão fixo, entretanto, surge também a figura dos switchers, que se alternam entre posições de dominação e submissão em momentos diferentes com os mesmos parceiros ou não. O Adepto B é contundente ao afirmar que os switchers não são parte do BDSM e sim parte de uma "camada caótica dos fetiches", na qual tudo é permitido. Há também aqueles que, como Adepto $\mathrm{C}$, entendem que ser switcher é também algo da essência de determinados indivíduos, e por isso, requer respeito.

Ninguém escolhe ser switcher, ou é, ou não é. Pode ser que a descoberta desta vertente aconteça em momentos diferentes da vida, mas [,] por princípio[,] esta natureza é inata. Embora a existência de um(a) switcher seja uma realidade, não há consenso quanto a sua aceitação no meio BDSM. Ainda existe preconceito quando alguém se assume switcher, sobretudo quando esta figura é masculina. Os preconceitos mais comuns são: do homem switcher, geralmente está associado, de forma pejorativa à bissexualidade, ou questionam a sua capacidade de dominar, uma vez que "quem se submete não sabe dominar". Já a mulher switcher é vista como aquela que domina seus escravos(as) e até mesmo o seu ou sua Dono(a). Esta rejeição já foi pior em anos passados, observa-se uma evolução no sentido de aceitar melhor esta forma de se viver o SM.

A partir desta explicação dos preconceitos que recaem sobre homens e mulheres switchers, pode-se reconhecer o peso que os papéis de dominação e submissão possuem na hierarquia de poder BDSM. Entre os homens, o papel de submissão é mais forte que o de dominação, marcando-o de tal forma que não se crê possível que um submisso em uma performance possa ser um dominador em outra. Já entre as mulheres, é o papel de dominação que prevalece, impedindo-a de ser uma submissa. Essa combinação é extremamente interessante, pois subverte o sistema dos papéis "ativo", associado ao homem, e "passivo”, à mulher. É como se, quando se é capaz de experimentar uma condição diferente daquilo que foi socialmente reconhecido, esse rompimento possua uma força tal que inviabiliza um "retorno" ao que era esperado. Por esse mecanismo, os preconceitos contra os switchers acabam por reiterar a hierarquia dos papéis "ativo" e "passivo" ainda em vigor na sociedade, e que tão bem foram abordados por Misse ${ }^{20}$.
Ao longo dessa pesquisa, obtive acesso a apenas uma fala de um switcher, que foi entrevistado no documentário Algolagnia ${ }^{21}$. Ele denuncia o desconforto que suas preferências eróticas causam ao meio. É possível que este desconforto se justifique porque o BDSM se pauta na dominação e na submissão como elementos excludentes da essência de cada indivíduo. A partir dessa essência, cada adepto assume a posição correspondente na hierarquia.

O desejo intenso de manter a ordem, seja ela qual for, faz eco à necessidade de ordem que todas as sociedades apresentam e que foi tão contudentemente explicitada pelo trabalho de Douglas ${ }^{22}$. A desconfiança sentida por quem ou pelo que representa ambiguidade social está relacionada à necessidade social de manter a ordem, o que significa requerer que cada um e cada coisa tenha o seu lugar claramente definido na estrutura social. Categorias fluidas, como a dos switchers, incorporam o medo social do que está fora da ordem e por isso, comumente, são deslegitimadas.

Dominadores, submissos e switchers eis as personas que povoam o universo BDSM. Para além de meras posições em um jogo erótico, a dominação ou submissão é parte da essência de cada um, segundo seus adeptos, ao mesmo tempo em que nem todas as pessoas a possuem. Neste sentido, a essência ganha conotação de orientação sexual ainda que requeira um aprendizado. $\mathrm{O}$ alinhamento entre orientação sexual e aprendizado e o pertencimento ao grupo (que será trabalhado no próximo subitem) conferem ao indivíduo autenticidade em sua prática sexual. Considerando os riscos envolvidos nas práticas BDSM, mister se faz discernir os verdadeiros dos falsos dominadores. Cabe agora perscrutar alguns elementos contidos nas narrativas reflexivas do grupo que permeiam o estilo de vida BDSM.

\section{BDSM: Um estilo marcado pelo cuidado com o corpo e o fortalecimento do self}

Retomando o pensamento de Giddens ${ }^{19}$, "estilo de vida" diz respeito a um conjunto de práticas, de certa forma, integradas, rotinizadas, que envolvem os modos de vestir e comer, por exemplo, e que se constituem como base material para uma narrativa reflexiva singular da autoidentidade do sujeito que o adota. É sobre esta narrativa particular que se pretende debruçar aqui tentando depreender sua articulação com o imaginário específico da contemporaneidade.

Produzir-se como um "estilo de vida" permite ao BDSM também constituir-se como uma sub- 
cultura $^{18,23,24}$, na qual essas sexualidades dissidentes podem se expressar, defendendo o cuidado do corpo e o fortalecimento do self, o que forja um erotismo politicamente correto, como proposto por Gregori ${ }^{25}$, que pretende atenuar os traços e conteúdos violentos envolvidos nas práticas sadomasoquistas.

Um dos elementos do imaginário BDSM faz referência à noção da prática sexual como técnica corporal, conforme Gregori ${ }^{26}$, cuja finalidade é o desenvolvimento interior dos envolvidos. Weiss ${ }^{12}$ vê o BDSM como técnica ou habilidade e como visão de mundo; “técnica de si”. Isso pode ser percebido na fala do Adepto C, um sádico assumido:

Em minha fantasia, a prática das sessões [...] São situações difíceis, mas ao vivê-las a escrava tem condição de expandir seus limites, além de tornarem-se mais próximas a mim, já que me dá especial prazer, no contexto da fantasia, ver as pessoas que amo sofrer. É uma forma significativa de crescimento para todas as partes e em todos os sentidos, pois entendo que o SM só se fortalece em comunidade.

O "crescimento" dos envolvidos, defendido pelo Adepto C, está associado à superação de padrões ou conceitos previamente estabelecidos acerca da sexualidade. Está ligado também a um desenvolvimento individual de acordo com o papel que cada um desempenha no universo BDSM, ou seja, de dominação ou submissão. Assim, pode-se falar sobre um "crescimento como escravo" ou um "crescimento no estilo de vida FemDom" (dominação realizada por mulheres), por exemplo. Logo, "crescimento" sinaliza a existência de conhecimentos e experiências que requerem o engajamento no meio para que sejam adquiridos. O "crescimento", que propicia a autorrealização, contém também a promessa psicológica e política de felicidade. O "crescimento" é para todos, conforme afirmação do Adepto C, mas essa categoria aparece com mais recorrência no discurso acerca da submissão, por conta da exigência de superação de tabus, preconceitos, limites físicos e psíquicos.

A superação de limites e o progresso de sua persona BDSM enquanto tal encontram no meio sua confirmação, que também exerce controle sobre os envolvidos, assegurando o respeito aos princípios estabelecidos, entre eles, o SSC. Outro lema comum nessa comunidade é " $[\mathrm{m}]$ achucar sem maldade (ou danos)" ${ }^{\prime 2}$. Esta regra parece circunscrever o ato de infligir dor dentro dos limites do outro, por isso não machuca, para que ambos obtenham prazer. Ainda assim, sinaliza uma vivência sempre no limite da fronteira, o que pa- rece denunciar o prazer pelo risco, pelo perigo. Prazer e perigo estão sempre implicados nessas práticas $^{26}$. Essa vigilância mútua pode conduzir à expulsão de indivíduos cujas condutas possam prejudicar adeptos ou o grupo como um todo. Trata-se, portanto, de um mecanismo de autoproteção e defesa, regulação e controle, bastante difundido no meio ${ }^{28,29}$, mas também um elemento do rito de reconhecimento social. Nesse sentido, a pesquisadora Weiss ${ }^{12}$ chega a afirmar que uma pessoa só se torna realmente praticante de BDSM quando participa de uma comunidade social, sexual e educacional, que ensina técnicas de autocontrole ao lado de cordas de bondage e habilidades de amarração. Esse compromisso com a comunidade é uma forma de pertencimento social, que diferencia o BDSM como uma comunidade de prática. Entretanto, no exercício desse controle, a autora percebe ambiguidade no discurso do grupo: por um lado, defende um projeto de autocontrole; por outro, exerce um acentuado controle externo sobre seus participantes.

Em “O império dos sentidos”, Duarte ${ }^{30}$ propõe o que denominou de "dispositivo de sensibilidade", do qual ressaltou três aspectos: a perfectibilidade, a experiência e o fisicalismo. A perfectibilidade está associada à capacidade própria à espécie humana de aperfeiçoamento contínuo, de progresso, que implica o uso sistemático da razão para o avanço do ser humano sobre o mundo. A perfectibilidade requer a experimentação do mundo exterior. A razão viceja por meio do contato sensorial dos sujeitos com o mundo. É por meio dos sentidos que a espécie humana constrói novas formas de se relacionar com o exterior a fim de promover seu desenvolvimento. Como bem pontua o autor, os sentidos estão na base da razão tanto quanto na da 'imaginação' ou das 'emoções' e 'paixões'. Assim, o fato cognitivo da 'experiência' é também fato emocional. Perfectibilidade e experiência estão intimamente relacionadas, já que não é possível o desenvolvimento humano sem a experimentação do mundo.

Diante do exposto, é possível reconhecer na ideia de "crescimento", tão propalada no universo BDSM, uma profunda relação com o fenômeno da perfectibilidade defendido por Duarte, uma vez que está associada à superação dos limites humanos, sejam eles físicos, psicológicos ou emocionais. Embora os limites do submisso devam sempre ser respeitados, cabe aos dominadores buscar lentamente promover nos submissos o desejo de superar as barreiras impostas por medos, traumas, preconceitos, ajudando-os a libertar-se dos mesmos; a exploração das interações; 
a redefinição dos limites da dor e do prazer com a mudança da concepção de onde começa um e termina o outro.

Por fim, o fisicalismo completa um "quadro aproximativo" entre as formas modernas da sexualidade e da sensualidade. Nas palavras de Du$\operatorname{arte}^{30}$ :

O fisicalismo, como teoria da pessoa, é uma revolução cosmológica, uma transformação crucial que ocorre também nesse período, decorrente da separação radical entre o corpo e o espírito (expressa, por exemplo, na filosofia de Descartes) e graças à qual se passa a poder considerar a corporalidade humana como dotada de uma lógica própria, que deve ser descoberta e que tem implicações imediatas sobre a condição humana. Na verdade, é a consideração da corporalidade em si, como dimensão autoexplicativa do humano, que se pode chamar propriamente de fisicalismo.

Da mesma forma que a perfectibilidade e a experiência são dimensões da vivência BDSM, o fisicalismo também está presente e pode ser percebido, por exemplo, na busca por um prazer erótico, muitas vezes não genital, pela exploração da mente (dominação psicológica e emocional) e do corpo, permitindo a descoberta de novas formas de se viver a sexualidade.

Em vista disso, pode-se afirmar que perfectibilidade, experiência e fisicalismo se congregam nas práticas BDSM. Tanto Gregori ${ }^{31,32}$, que vem desenvolvendo pesquisas a respeito de práticas sexuais, limites da sexualidade e violência, quanto Zilli ${ }^{18}$, que analisou o discurso de legitimação das práticas BDSM na internet, observam que as práticas BDSM revelam certo cálculo racional do uso do prazer para maximizar sua intensidade e minimizar os riscos decorrentes dessas práticas. O SSC revela-se mais um instrumento dessa lógica e reforça um erotismo politicamente correto embebido em um imaginário tão caro à Contemporaneidade.

\section{Considerações finais}

Os praticantes de BDSM demonstram no ciberespaço a preocupação em definir e esclarecer seus princípios, identidades e práticas, a fim de afastar pessoas mal intencionadas de seu meio. $\mathrm{O}$ BDSM organiza-se a partir de uma rígida hierarquia, na qual as posições de dominação e submissão eróticas são pensadas pelo grupo como parte da identidade de cada sujeito. Ou seja, a dominação está na natureza do dominador, assim como a submissão faz parte da essência da pessoa que se submete, constituindo-se em uma orientação sexual. Por conta disto, os switchers, que ora assumem o papel de dominadores ora de submissos, são vistos com desconfiança. Ao contrário do que comumente se imagina, alguns adeptos defendem que é a pessoa submissa que detém o poder de definir os limites da prática. Afinal, os submissos neste meio possuem agência em suas relações, estabelecendo consensualmente com seus potenciais dominadores a forma como desejam ser submetidos. A primeira vista, poderia-se afirmar que a hierarquia BDSM subverte sutilmente as tradicionais posições de poder. No entanto, dominador e submisso devem ser apreendidos sempre de forma relacional, um forma o outro em um ciclo contínuo, sendo, no fundo, difícil dizer quem domina e quem se submete. $\mathrm{O}$ peso do chicote liga a mão que o empunha ao corpo que o recebe.

O ciberespaço não produziu o BDSM, mas, sem dúvida, alargou os horizontes de seus adeptos, permitindo a comunicação e a troca de informações com praticantes do mundo inteiro e promovendo seu estilo de vida. O BDSM, como subcultura, pode ser pensado da perspectiva de Duarte ${ }^{30}$, que reconhece, na combinação do dispositivo da sensibilidade, terreno profícuo para o surgimento de novos comportamentos sexuais, entre os quais se pode incluir o BDSM. Esses novos comportamentos, tal como já acontece no BDSM, decorrem da incitação à sensibilidade em um sentido amplo, um estilo de vida que privilegia o novo em detrimento ao "tradicional", o acelerado desenvolvimento de tecnologias voltadas para o corpo (dos brinquedos sexuais a técnicas de amarração do corpo, por exemplo), o que inclui a otimização do uso do corpo (o sexo que transcende os órgãos genitais; os limites físicos e psíquicos, que precisam ser paulatinamente superados para o crescimento dos submissos).

É certo que esta subcultura encontra confluência com outros paradigmas da Contemporaneidade, como a busca pelo máximo desenvolvimento da potencialidade de cada um, por meio do autoconhecimento e do autodesenvolvimento e o uso da razão na experimentação do mundo atrelada à exacerbação da sensorialidade. A despeito, portanto, do estigma que recai sobre o grupo, este quadro de análise parece indicar que as práticas BDSM, ao menos no que diz respeito a como se apresentam virtualmente, estão inseridas por completo entre os pilares da subjetividade contemporânea.

Retomando o tema para o campo da Saúde Coletiva, propõe-se o aprofundamento do olhar 
científico não apenas sobre a subcultura BDSM, mas também sobre as diversas sexualidades dissidentes, haja vista a escassez de pesquisas nesta temática. Neste sentido, sugere-se também investigar os malefícios que as definições de patologia implicam na saúde daqueles que a recebem (particularmente o sadomasoquismo, já que a recomen- dação de despatologização apresentada por Reiersol e Skeid 5 foi ignorada pela Associação Americana de Psiquiatria). Com estas pesquisas, espera-se a promoção da saúde, com o fim de iniquidades decorrentes de diagnósticos médicos/psi, atravessados por moralidades que não cabem mais em um tempo que clama pelo respeito à diversidade.

\section{Referências}

1. Paim JS, Almeida Filho N. Saúde coletiva: uma "nova" saúde pública ou campo aberto a novos paradigmas? Rev Saude Publica 1998; 32(4):299-316.

2. Buss PM, Pellegrini Filho A. A saúde e seus determinantes sociais. Physis 2007; 17(1):77-93.

3. Gayle R. Thinking Sex: Notes for a Radical Theory of Politics of Sexuality. In: Vance C, editor. Pleasure and Danger: Exploring Female Sexuality. Nova York: Routledge; 1984. p. 143-178.

4. American Psychiatric Association. Manual diagnóstico e estatístico de transtornos mentais: DSM-5. $5^{\mathrm{a}}$ ed. Porto Alegre: Artmed; 2014

5. Reiersol O, Skeid S. The ICD 11 Revision: Scientific and Political Support for the Revise F65 Reform. Second Report to the World Health Organization. Oslo: World Health Organization; 2011.

6. Lanteri-Laura G. Leitura das perversões: história de sua apropriação médica. Rio de Janeiro: Zahar; 1994.

7. Leite Júnior J. Elementos para uma história do conceito de sadomasoquismo [Relatório final da bolsa de Iniciação Científica PIBIC-CNPq do Projeto "Repercussões de Sade"]. São Paulo: PUC; 2000.

8. Mcclintock A. Couro imperial: raça, travestismo e o culto da domesticidade. Cadernos Pagu 2003; 20:7-85.

9. Brame GG, Brame WD, Jacobs J. Different Loving: The World of Sexual Dominance \& Submission. Nova York: Villard; 1993.

10. Rubin G, Butler J. Tráfico sexual - entrevista. Cadernos Pagu 2003; 21:157-209.

11. Califia P. A personal view of the history of the lesbian S/M community and movement in San Francisco. In: Samois. Coming to power. Boston: Alyson Publications; 1987. p. 243-287.
12. Weiss M. Techniques of Pleasure: BDSM and the Circuits of Sexuality. Londres: Duke University Press; 2011.

13. Silva VLM. Sob a égide do chicote: Uma leitura acerca do amor na contemporaneidade [tese]. Rio de Janeiro: Pontifícia Universidade Católica do Rio de Janeiro; 2015.

14. Conselho Nacional de Saúde. Resolução número 510, de 07 de abril de 2016. [acessado 2018 Mar 29]. Disponível em: http://conselho.saude.gov.br/resolucoes/2016/reso510.pdf

15. Minayo MCS. O desafio do conhecimento: pesquisa qualitativa em Saúde. São Paulo: Hucitec Editora; 2014

16. Fragoso S, Recuero R, Amaral A. Métodos de pesquisa para internet. Porto Alegre: Sulina; 2013.

17. Zilli BDC. BDSM de A a Z: a despatologização através do consentimento nos "manuais" da internet. In: Díaz-Benítez ME, Fpigari CE, organizadores. Prazeres dissidentes. Rio de Janeiro: Editora Garamond; 2009. Coleção: Sexualidade, gênero e sociedade. p. 481-508.

18. Zilli BDC. A Perversão domesticada-estudo do discurso de legitimação do BDSM na internet e seu diálogo com a psiquiatria [dissertação]. Rio de Janeiro: Universidade do Estado do Rio de Janeiro; 2007.

19. Giddens A. Modernidade e identidade. Rio de Janeiro: Zahar; 2002.

20. Misse M. O estigma do passivo sexual: um símbolo de estigma no discurso cotidiano. Rio de Janeiro: Achiame; 1979.

21. Algolagnia: a doc about BDSM Scene in Brazil/RJ [video online]. Rio de Janeiro: Distribuição de Túlio Bambino, Henrique Santana e José Viana Filho; 2006. [acesso em 2014 Set 2]; 29h30min., sonoro e legendado. Disponível em: https://www.youtube.com/watch? $\mathrm{v}=\mathrm{w}-$ T1PtjffzkQ 
22. Douglas M. Pureza e perigo. São Paulo: Perspectiva; 1966.

23. Leite Júnior J. Das maravilhas e prodígios sexuais: a pornografia "bizarra" como entretenimento. São Paulo: Annablume; 2006.

24. Gregori MF. Práticas eróticas e limites da sexualidade: contribuições de estudos recentes. Cadernos Pagu 2014; 42(1):47-74.

25. Gregori MF. Prazeres perigosos: contrato, consentimento e a erotização de corpos em cenários sadomasoquistas. Revista Etnográfica 2015; 19(2):247-265.

26. Gregori MF. Prazer e perigo: notas sobre feminismo, sex-shops e S/M. In: Piscitelli A, Gregori MF, Carrara S, organizadores. Sexualidade e saberes: convenções e fronteiras. Rio de Janeiro: Garamond; 2004. p. 235-255.

27. Leite Júnior J. A cultura SerM [monografia]. São Paulo: PUC; 2000.

28. Facchini R. Comunidades imaginadas: uma reflexão a partir de mulheres que têm relações erótico-afetivas com mulheres no "meio BDSM". In: GAT 7: Sociabilidades, práticas sexuais dissidentes e marcadores de diferença do VIII ENUDS. Unicamp, Campinas; 8 a 12 out. 2010.

29. Melo ML. A dor no corpo: identidade, gênero e sociabilidade em festas BDSM no Rio de Janeiro [dissertação]. Rio de Janeiro: Universidade do Estado do Rio de Janeiro; 2010.

30. Duarte LFD. O império dos sentidos: sensibilidade, sensualidade e sexualidade na cultura ocidental moderna. In: Heilborn ML, organizadora. Sexualidade: $o$ olhar das ciências sociais. Rio de Janeiro: Zahar; 1999. p. 21-30.

31. Gregori MF. Relações de violência e erotismo. Cadernos Pagu 2003; 20:87-120.

32. Gregori MF. Limites da sexualidade: violência, gênero e erotismo. Revista de Antropologia 2008; 51(2):575-606.

Artigo apresentado em 31/01/2018

Aprovado em 06/03/2018

Versão final apresentada em 03/07/2018 